\title{
Memória e historiografia: limites e possibilidades de uma aproximação*
}

\author{
Márcia Mansor D’Alessio**
}

A HISTÓRIA, QUE NA PRIMEIRA METADE do século XX abrigou, no interior de seus domínios, críticas, questionamentos, disputas por hegemonia, chega aos anos 70 ostentando uma produção tão ousada quanto diversificada e uma importante reflexão acumulada sobre essa produção, seus condicionamentos e suas perspectivas. O impulso de reordenar fronteiras desorganizadas pelo alargamento do campo historiográfico revela um movimento interno de busca de reconstrução de uma identidade ameaçada. No entanto, se os anos 60 e 70 foram marcados por criativa efervescência decorrente da discussão que historiadores vinham travando sobre seu objeto e seu ofício, os anos 90 sofreram o impacto do que se identificou como uma perda de paradigmas, decorrente, dentre outros fatores, da intervenção na historiografia do fato histórico decisivo que instaurou o que se pode chamar de o fim de uma era, qual seja, a derrota da proposta socialista de organização da sociedade. O marxismo que, a despeito das reticências que sempre acompanharam sua aceitação, ocupara um lugar privilegiado na construção do conhecimento durante todo o século 20, teve seu prestígio abalado com o fim do comunismo. Por ter elaborado uma síntese da

* Trabalho apresentado no II Encontro Regional Sul de História Oral, realizado em São Leopoldo/RS, em maio de 2001. Elaborado a partir da obra: D'Alessio, Márcia M. Reflexões sobre o Saber Histórico; entrevistas com Pierre Vilar, Michel Vovelle, Madeleine Rebérioux. São Paulo, Ed. UNESP, 1998.

* Professora do Departamento de História da PUC-SP. 
história da humanidade das mais coerentes, acompanhada de conceitos operatórios extremamente eficientes, a ausência de Marx priva os cientistas sociais de um poderoso referencial conceitual, o que veio aprofundar as incertezas epistemológicas daquele conturbado contexto histórico.

Essas foram as motivações que me levaram, nos anos 90, à idéia de entrevistar Pierre Vilar, Michel Vovelle e Madeleine Rebérioux.

$\mathrm{O}$ interesse pela reflexão de historiadores franceses deve-se ao papel exercido pela França nas inovações e renovações do campo historiográfico e ao intenso diálogo existente entre historiadores franceses e brasileiros. Madeleine Rebérioux, Michel Vovelle e Pierre Vilar, cujas obras são referenciais importantes da produção historiográfica de nosso século, têm grande penetração no Brasil e significativa participação na formação de nossos pesquisadores.

Pierre Vilar é um representante típico da clássica historiografia francesa. Sua história de vida acompanha a história do século XX, sua obra é a expressão das revoluções pelas quais passou a produção historiográfica contemporânea, seu método revela a influência das principais matrizes teóricas e tendências historiográficas de nossa época.

$\mathrm{O}$ respeito às fontes e a eleição da história como referencial de verdade, colocam-no na herança da luta dos historiadores da Escola Metódica contra as generalizações abstratas das Filosofias da História. Mas sua participação ativa nos debates e nas práticas historiográficas que construíram as propostas do grupo dos Annales revelam seu pertencimento à esta "Escola". Na realidade, é visto como o marxista dos Annales. Isto porque, como todos os historiadores de seu tempo, sofreu enorme influência do arcabouço teórico marxiano e, mais do que todos os outros, apropriou-se dele. Junto com os outros “analistas" construiu a noção de totalidade, expressando uma concepção de tempo cuja elaboração passa pela percepção das múltiplas durações dos fatos históricos. Diferentemente de seus pares, encontra nesta totalidade um princípio fundante, as condições materiais de existência dos homens, para ele, locus privilegiado de feitura da história.

Mestre de vários historiadores de seu tempo e de gerações subseqüentes à sua, Pierre Vilar define a historiografia francesa do século XX.

Michel Vovelle é um dos mais importantes expoentes da história das mentalidades, campo de investigação mais precisamente delimitado a 
partir da formulação, pelo grupo dos Annales, da "longa duração", noção que possibilitou a percepção das permanências e a construção do conceito de mentalidade. No entanto, esse tempo longo é captado na sua inter-relação com o seu oposto, o tempo curto, nervoso, ágil, tempo da ruptura, da descontinuidade e tempo onde se localizam as ações políticas, aquelas que organizam o cotidiano da vida coletiva.

Em seus estudos - sobretudo aqueles referentes à Revolução Francesa, em que observa as lutas políticas imediatas e as sensibilidades coletivas seculares - essa dialética resulta em um mosaico contraditório na sua composição, quase um caleidoscópio nas ágeis e infinitas possibilidades de combinação de seus elementos. $O$ resultado é a emergência do fato histórico em toda sua complexidade, anteriormente minimizada por reconstruções globalizantes, negligentes das sutilezas da aventura humana. Esse mosaico caleidoscópico, trazendo à tona tempos, culturas, memórias, mentalidades numa coexistência simultânea e mutante, fabrica a trama ou, em outras palavras, realiza a totalidade histórica praticada também por Michel Vovelle.

Madeleine Rebérioux pertence a uma geração e a um grupo de historiadores franceses que mergulhou profundamente nas investigações sobre a classe operária, revisitando criticamente os estudos anteriormente realizados e imprimindo-lhes perspectivas diferentes daquelas estabelecidas apenas pelo discurso construído na prática da militância. Campo de reflexão e forma de abordagem comuns criaram um lugar de identificação desses historiadores que, há décadas, mantém interesses convergentes e uma interlocução que resulta em produção historiográfica rica e abundante.

Os objetos de investigação da autora situam-se na dimensão política da história: República, movimentos revolucionários, as Internacionais, Primeira Guerra, socialismo, lideranças socialistas (principalmente Jean Jaurès), extrema direita e racismo. Sua visão do político contempla, além das lutas imediatas, o simbólico, o cultural, o cotidiano de classes e grupos populares. Seus textos sobre temas ligados à memória revelam as infinitas possibilidades de abordagem das questões políticas.

Em artigo que integra a obra organizada por Pierre Nora, Les lieux de mémoire (1994), Rebérioux analisa o Muro dos Federados, que fica no cemitério Père Lachaise e onde foram mortos os combatentes da Comuna de Paris (1871) em seu último enfrentamento com as forças 
da repressão. Esse estudo revela como sujeitos sociais resgatam um fato esquecido - o massacre dos revolucionários - através da construção de uma memória em torno de um lugar, o Muro dos Federados; e como um lugar de memória torna-se lugar de disputas e arranjos políticos. Seja como fator de coesão de grupos em conflito, seja como lugar de enfrentamento de facções adversárias, a memória pode tornarse elemento constitutivo de lutas políticas do presente. Do ponto de vista metodológico, é importante perceber seu papel no encaminhamento dos conflitos, na reorganização da correlação de forças, enfim, na instituição de fatos históricos.

Os três historiadores entrevistados têm em comum o fato de terem participado das grandes revoluções ocorridas na historiografia francesa do século XX e de pertencerem ao mesmo universo ideológico.

Por ter tido a entrevistadora um objetivo muito específico, qual seja, ouvir depoimentos dos historiadores sobre o saber histórico de nosso tempo, foram elaboradas questões específicas, apresentadas sob a forma de problemáticas. Dos oito temas propostos, apenas um escapa da discussão teórico-metodológica "strictu sensu", referindo-se a uma questão política atual. São eles:

História e Representação

História e Cultura

Mídia e História

A dimensão psicológica da História

Identidade Coletiva e História

O Retorno da história política

Questão Nacional

Formas do conbecer histórico

Os critérios para a escolha dos entrevistados foram: a relevância de suas obras e sua penetração no Brasil; a geração a qual pertencem; suas posturas ideológicas. Questões afetivas também motivaram minhas escolhas: a amizade e admiração por Pierre Vilar desenvolvidas na relação orientador/orientanda; o respeito por Madeleine Rebérioux a quem conheci pessoalmente por sua participação em minha banca de doutorado; a simpatia, à distância, por Michel Vovelle.

Em virtude das circunstâncias favoráveis, os contatos com os entrevistados foi simples. Todos me receberam em suas casas, após um 
telefonema no caso de P. Vilar, após cartas e telefonemas nos casos de M. Rebérioux e M. Vovelle.

Vilar, dizendo-me que precisaria refletir para responder, pediu-me que gravasse as questões e lhe desse um tempo para respondê-las. $\mathrm{O}$ material que Vilar, um dos maiores historiadores do século XX, entregou-me, foi riquíssimo: quatro fitas gravadas. Rebérioux e Vovelle responderam às questões no ato das respectivas entrevistas. O papel da entrevistadora foi o de propor as problemáticas. Não houve interferência no desenvolvimento da reflexão dos entrevistados.

Quatro questões foram colocadas a todos. As outras quatro foram distribuídas entre eles de acordo com seus interesses mais específicos.

De posse de todo o material, iniciei a transcrição das fitas, trabalho que em língua estrangeira apresenta, obviamente, maiores dificuldades do que o feito na língua materna de quem entrevista. Por se tratar de depoimentos, mesmo nas reflexões mais científicas aparece o tom coloquial e, conseqüentemente, surgem termos e expressões não usuais no vocabulário de obras escritas. Além disto, são mencionadas pessoas, situações, lugares vindos do universo mais privado dos entrevistados e desconhecidos do público mais amplo. Em função destas dificuldades, as fitas foram ouvidas inúmeras vezes. $\mathrm{O}$ aspecto prazeroso foi a familiaridade com as falas que a repetição propiciou e a maior percepção dos intervalos, das interjeições, da serenidade, da indignação, enfim, daquilo que está além das palavras e que faz a riqueza da oralidade.

Após a transcrição, os textos foram enviados aos entrevistados para conferência. Quando retornaram, iniciei o trabalho de tradução que apresentou algumas das dificuldades da audição. Foram usados vários dicionários na tentativa de precisar bem palavras contidas em formulações às vezes mais carregadas de subjetividade. A tradução de depoimentos que trazem saberes científicos perpassados por memórias mostrou-se mais complexa do que a de textos "técnicos".

Terminada a tradução, as entrevistas, com a autorização dos autores, foram transformadas em livro e publicadas pela Editora UNESP.

$$
\text { *** }
$$

História e memória têm algo em comum: ambos os termos carregam um duplo significado; história quer dizer, ao mesmo tempo, a experiência coletiva dos homens e a elaboração intelectual sobre ela; 
memória significa registro e armazenamento, mas também evocação do que foi registrado e armazenado (ver Le Goff, 1984). A advertência é necessária. Ela nos possibilita trabalhar melhor com os dois fenômenos que, além da duplicidade de significados, aparecem indistintamente entrelaçados nos discursos do cotidiano.

Com quais significados e no que se aproximam ou se distanciam memória e história?

Halbwachs, no seu clássico A Memória Coletiva (1990), marca a diferença entre os dois fenômenos e para a história de sua época tece críticas. A História, sugere, empobrece o real "assemelha-se a um cemitério...” (Ibid, p. 55) pois se atém à sucessão de datas e fatos. O tempo da história é homogêneo, não é o tempo dos múltiplos grupos que compõem o social, o que o torna exterior aos indivíduos. A esta história ele chama história escrita para distingui-la do que considera história vivida, à qual entrelaça a memória coletiva. Com efeito, para Halbwachs é sobre a história vivida que se constrói memória e a história vivida é a fusão entre o mundo interior individual e a sociedade. Portanto, a memória não é um quadro abstrato e artificial, o que a coloca em oposição à historia escrita que começa onde a memória acaba, e esta acaba quando não tem mais como suporte um grupo cujo desaparecimento estimula a fixação das lembranças por escrito. A memória não mais vivenciada produz uma história "fora dos grupos e acima deles" (Ibid., p. 82), portadora de um tempo fragmentado que fixa datas de uma vez por todas, congelada, imóvel. Parece fácil perceber que a história que Halbwachs opõe à memória é a história-conhecimento.

Os estudiosos da memória são praticamente unânimes em afirmar que o atual prestígio da memória se deve à aceleração do tempo na contemporaneidade e ao medo do desaparecimento das lembranças. Povos desprovidos de lembranças correm o risco de não saberem quem são. A conseqüente profusão de estudos sobre a memória seduziu a história e, no limite, modificou-lhe a escrita. As emoções do lembrar e seu uso pelo historiador desmancham a rigidez da reflexão científica e a aridez de seu discurso. Embora a oposição permaneça, memória e história-conhecimento estão mais próximas, a primeira em colaboração com a segunda.

O resultado desse trabalho com os historiadores entrevistados o coloca, ao mesmo tempo, no campo da memória e no da historiografia. 
Ele é produção de saber histórico à medida que os autores refletem cientificamente sobre objetos de investigação propostos, mas é memória porque fazem uso de suas lembranças para construir esta reflexão. As lembranças introduzem a subjetividade em seus textos, flexibilizando discursos e liberando-os da estabilidade que o método da escrita da história exige. Suas sensibilidades ganham espaço nas análises e misturam-se, sem tensões, às reflexões objetivas acumuladas em vidas inteiras de pesquisas rigidamente apoiadas em documentação e método.

A primeira questão, História e Representação, foi assim colocada:

"A palavra representação tem estado muito presente no vocabulário dos estudos históricos desde a última década. Há os que argumentam ser a representação o único interesse do historiador, já que a história é registrada a partir de interpretações, sendo ela própria, portanto, uma representação. O que seria representação na experiência coletiva dos homens? Como pode ser vista a questão do real em relação à representação, da historiografia em relação à história, em suma, como abordar hoje a questão da verdade/objetividade uma vez que a aceitação da diversidade multiplica os pontos de vista e as interpretações não têm necessariamente na História seu referencial?”

Ao abordá-la, Pierre Vilar começa sua exposição colocando um problema estritamente pessoal, privado, íntimo:

"Você sabe que já há alguns anos, venho tendo muita dificuldade para ler e nos últimos meses perdi completamente a possibilidade da leitura. Em função disso tenho a sensação de estar completamente defasado em relação ao que se publica. É provável, então, que não responda muito bem às suas questões. Você me dirá e teremos assim uma boa ocasião de retomar um debate entre nós".

A partir daí, toda sua explanação é carregada de recordações. A Escola de Altos Estudos, local que abrigou - e abriga - as revoluções protagonizadas pelas várias gerações dos Annales, é muito evocada, o que nos remete à importância do espaço para a memória. A estabilidade 
do espaço referencia materialmente e concretamente o passado. A Escola de Altos Estudos, para Pierre Vilar, tornou-se um "lugar de memória". Diz ele:

"Nesse terreno, tenho ainda uma outra recordação, sempre, naturalmente, ligada à nossa École des Hautes Études que, em princípio, surgiu para reunir as metodologias das diferentes disciplinas que compõem as Ciências Humanas. Há uns quinze anos atrás, nosso colega André Piatier - um economista matemático muito rigoroso sobre a originalidade desta disciplina, mas aberto a outras abordagens - convidou um economista italiano, cujo nome me escapa, e a mim para ouvirmos Jean-Pierre Vernant explicar que a noção de trabalho, a representação do fato trabalho na Grécia era algo completamente mítico, muito incompreensível para nós e que, conseqüentemente, devia ser utilizada com muita prudência pelos historiadores atuais. Em suma, o trabalho era visto como uma espécie de mito. Nosso colega italiano brincou dizendo: 'sabem, eu tenho um contrato muitíssimo bem remunerado com a Universidade norte-americana. Eu lhes asseguro que este tipo de remuneração e este tipo de trabalho são completamente míticos para a mentalidade americana'. Ele estava brincando, bem entendido, mas creio que relativizou bastante a questão."

O relato de uma situação vivida, feito por Vilar para explicar o binômio real/representação, é mais esclarecedor que qualquer teoria. Evocando suas lembranças ele diz:

"Ainda uma recordação pessoal: você sabe que em 1937, menos de um ano depois do início da guerra civil na Espanha, a Legião Condor, a legião dos Alemães nazistas posta à disposição do General Franco, bombardeou a pequena cidade basca de Guernica destruindo-a completamente. Este prenúncio daquilo que deveria ocorrer tão tragicamente nos anos seguintes deixou, evidentemente, nos homens que o vivenciaram e naqueles que o viram acontecer, uma lembrança inesquecível. Quando do cinqüentenário deste fato, 
em 1987, fui ver em Guernica como se celebrava esta lembrança e como as pessoas representavam este episódio. Estava lá com um historiador americano, Soutworth, que estudou admiravelmente o fenômeno e pudemos ver o quanto a lembrança de Guernica estava presente nessa vila destruída, depois reconstruída e, como as pessoas que haviam vivido aquilo no passado o viviam ainda no presente. Por outro lado, isto deixou marcas profundas na realidade basca de hoje, já que existem ainda homens armados querendo defender uma determinada visão do povo basco.

Quando voltei a Paris, acatei a sugestão de um de meus colegas para falar sobre esse assunto a alguns alunos que convidaríamos. Durante minha exposição perguntei: 'Para vocês, o que é Guernica?’ Eles me responderam rápida e brevemente: 'Guernica é um quadro!'”

Ainda com o objetivo de mostrar a diferença entre real e representação, relembra uma anedota que ouvia em tempos passados:

“Conta-se que Picasso, durante a ocupação alemã em Paris, foi interrogado por um oficial alemão que lhe perguntou: 'Foi você que fez Guernica?' Ao que ele respondeu: 'Não, foi você!' Não se sabe ao certo se a anedota é exata, mas - de qualquer maneira - ela é muito pertinente. É evidente que há representação, mas não se pode esquecer o fato.”

Interrogada sobre a mesma problemática, Madeleine Rebérioux deu elementos importantes sobre a história da historiografia da classe operária, baseada em suas próprias memórias:

“É verdade que o historiador tem seu próprio sistema de representação e é capaz de criticá-lo (ou ao menos deveria sê-lo). Foi isto que fizemos com a história do movimento operário, quando criamos nos anos sessenta, na França, todas as nossas instituições de História operária: a revista Le mouvement social, o Institut Français d'Historie Sociale, o Centre d'Histoire du Syndicalisme, o Dictionnaire Biographique du Mouvement Ouvrier Français dirigido por Jean Maitron, sem esquecer a Société d'Études Jaurésienne". 
O relembrar de Madeleine Rebérioux mostra as representações historiográficas dialogando, e mesmo polemizando, na busca de melhores explicações do real:

"Todos se encontravam com a mesma vontade de elaborar um conhecimento sério do passado do movimento operário e da história social do país onde vivíamos e de outros países, ou seja, das forças operárias internacionais na Europa.

A capacidade que tivemos de afrontar, neste terreno, nosso passado militante, reafirmando sempre o desejo de não repetir tanto o que o Partido Comunista dizia em matéria de história operária, quanto o discurso anti-comunista da SFIO, ou mesmo os discursos cristão anti-ateu e ateu anticristão, consolidou equipes que permaneceram muito unidas, durante trinta anos ainda que os caminhos políticos tenham sido completamente divergentes.'

As subjetividades da historiadora aparecem na formulação de um conceito de memória extraído de vivências individuais e de grupo:

"Nós nos constituímos, assim, fora da corrente dos Annales, ainda que tenhamos escrito nos Annales. E isto se deu porque todos estávamos unidos no mesmo momento e com a mesma intenção em relação a nosso passado: não ficarmos presos à memória que as organizações das quais vínhamos nos davam do passado. Tínhamos uma enorme vontade de ver claro, de utilizar as armas que os historiadores, outras disciplinas ou outras escolas, como os Annales, nos propunham. É nesse sentido que disse, anteriormente, que entre memória e história há uma grande diferença. Penso que a coleta de memórias é indispensável aos historiadores mas que o próprio da história é de não se fechar nesta coleta."

História e Cultura foi outro tema proposto aos entrevistados. Sua formulação foi a seguinte:

"Existe hoje uma profusão de estudos históricos dirigidos a questões culturais. São inúmeras as razões que levaram 
a historiografia a privilegiá-las, mas não se pode deixar de sublinhar a influência da antropologia e da etnologia no campo da história, e o conseqüente aprofundamento das idéias de pluralidade e diferenças o que, do ponto de vista do conhecimento, pode significar um relativismo sem limites.

Qual a possibilidade de convivência entre um conhecimento histórico baseado na relação referência teórica/evidência empírica e relativismo? Mais precisamente, qual a possibilidade de construção de referências teóricas ou conceitos - úteis aos estudos históricos - em um contexto historiográfico no qual predomina o relativismo?

Por outro lado, não muito longe dessa ordem de problemática, há as questões do acaso e do imprevisível que, também, têm adquirido prestígio na reflexão histórica. Evidentemente, trata-se de conquista teórica importante, à medida que libera a história de esquemas rígidos e apriorísticos. No entanto, coloca uma série de indagações que merecem ser discutidas. Assim, se o imprevisível é considerado importante como elemento constitutivo do viver coletivo, é possível pensar a história-objeto como portadora de uma lógica? Se, a história-objeto não tem lógica, é possível ao conhecimento histórico continuar a trabalhar com conceitos? Por outro lado, se há uma lógica na história, qual o lugar de sua constituição?"

Pierre Vilar fez reflexões sobre todas as dimensões da questão colocada e sobre o papel do acaso nas transformações da história disse:

"Em relação às grandes transformações históricas, penso ser pouco questionável que tenham sempre sido trazidas, nas suas origens, pela ciência e pela tecnologia. Isto não pode ser contestado. Se nosso mundo atual não se assemelha ao mundo de 1900, é porque houve um certo número de transformações absolutamente marcantes e inesperadas. Quem teria pensado que seria possível deslocar-se de Paris a Tóquio em menos 24 horas? Este tipo de coisas inegavelmente transforma o mundo.

Outra coisa que me parece das mais impressionantes na história que vivi, é a multiplicação da população. Passamos 
de um bilhão de homens sobre a terra para cinco bilhões e repare que a intervenção de flagelos como a Aids, por exemplo, nos lembra o que deve ter sido a queda das populações americanas depois da invasão dos europeus. Eis aí grandes problemas que estão um pouco esquecidos. Sobre isso permita-me ainda relembrar um episódio de minha vida. No curso dos anos 50, foi publicado um pequeno livro sobre a Catalunha, de uma historiadora inglesa muito respeitável dentro do estilo da história clássica. O livro tratava da evolução da Catalunha do fim do século XIII até a metade do século XV e a autora se perguntava por que, em um dado momento, a dinastia catalã chegou ao seu fim em função da morte de um rei sem filhos. Ou seja, a autora se filiava à visão da escola clássica catalã que vincula a decadência da Catalunha ao desaparecimento da dinastia catalã. A resenha desse livro, feita pelo hispanista francês Jean-Victor Angullon, terminava dizendo: é maravilhoso, é uma extraordinária lição de história, de um dia para o outro ninguém sabe o que vai acontecer, ninguém é capaz de explicar porque tal coisa existe etc. A única coisa que tinham esquecido - tanto a hispanista quanto o autor que a comentou - é que durante o período por ela estudado, a população catalã havia caído pela metade. É como se, em cem anos, a população da França tivesse caído a ponto de hoje ser vinte milhões de habitantes ao invés de cinqüenta e cinco milhões e isto desaparecesse das análises. Foi a partir desse tipo de questões que propus uma revisão da história catalã, lembrando, inclusive, que a demografia é um fenômeno fundamental e influi no destino político dos diferentes países."

Vilar evoca sua vivência histórica: "na história que vivi...”. Estamos aí no campo da memória ou da história? A própria indagação tem que ser pensada a partir dos mencionados significados das duas palavras. Já vimos que a história que se contrapõe à memória é a históriaconhecimento. Em contraposição, história-vida e memória se confundem, pois a vivência que produz história produz a matéria prima das lembranças. Nos termos de Halbwachs podemos falar de memória coletiva e memória histórica. O que distingui uma da outra? Talvez 
possamos dizer que a memória histórica é aquela que tem compromisso com a veracidade dos fatos lembrados, ao contrário da memória coletiva que relembra arbitrariamente (Nora, 1984). É o que se depreende da distinção feita pelo sociólogo, segundo Jean Duvignaud: memória histórica "supõe a reconstrução dos dados fornecidos pelo presente da vida social e projetada no passado reinventado"; memória coletiva é "aquela que recompõe magicamente o passado" (Duvignaud, 1990, grifos meus).

No caso da reflexão de Vilar acima citada, a memória histórica se entrelaça à produção de conhecimento histórico, aproximando, até o limite do possível, memória e historiografia.

O tema Midia e História foi assim proposto:

"Considerando-se o peso do presente sobre a história vivida em função, sobretudo, do papel da mídia na vida cotidiana, enfatizando o tempo imediato, qual seria a função do historiador na sociedade contemporânea?

Pode-se dizer que existe, atualmente, uma disponibilidade coletiva para o esquecimento do passado ou uma ameaça de ruptura na relação passado-presente?

O que significaria, para as sociedades, negligenciar o passado ou, no limite, esquecê-lo?"

O destino da memória é ditado pela história (vivida). O ritmo do tempo vivido preserva-a ou descarta-a. Também seu conceito é historicamente determinado: cada época a concebe de acordo com seu próprio perfil. É o que se depreende da reflexão de Michel Vovelle sobre a problemática acima colocada:

"Esta imersão no instante é acompanhada de uma erosão das formas herdadas da memória. Memória das sociedades tradicionais, de transmissão oral durante muito tempo veiculada pela família e pela comunidade, hoje esvanecente, em um ocidente onde o universo camponês do mundo rural se encolhe cada vez mais e a coabitação inter-gerações não está colocada na cidade moderna. Mas sabe-se, também, que esta memória, longe de ser um patrimônio inerte ou um tesouro que se deva preservar como o fizeram eruditos e 
folcloristas do século passado, é também e sobretudo uma recriação contínua, muito mais flexível do que se acreditou, reflexo da imagem que cada período cria do passado."

Da memória ameaçada pela temporalidade do efêmero, Vovelle passa à cultura algo perdida da Revolução Francesa. Evocando comportamentos, constata silêncios na memória coletiva:

"Uma certa cultura de base se desvanece, em um tempo em que a ênfase na importância dos conhecimentos científicos e tecnológicos parece colocar em desuso a pesada bagagem de um passado que se tornou importuno.

Dessa regressão, poderíamos dar, na França, uma ilustração significativa a partir do episódio recente da celebração do bicentenário da Revolução de 1789. Sondagens feitas diretamente com o público testemunham a erosão profunda de um corpus de conhecimento, ontem considerado como elementar, de atores e fatos marcantes do evento fundador e, mais ainda, a banalização que confina à indiferença os valores conquistados - liberdade, igualdade, fraternidade; nossos avós cantavam todas as estrofes da Marseillaise; minha geração lembrava-se de três; quanto das nossas crianças conhecem a primeira? No bit parade dos personagens ilustres, os clichês se cristalizam: Lafayette, caracóis na cabeça, seguido de Louis XIV e, no fim da lista, Robespierre, encarnando o personagem ingrato responsável pelo Terror."

Abordando a mesma problemática, Madeleine Rebérioux reflete sobre a relação passado/presente e seu papel na produção do conhecimento histórico. Ao fazê-lo, confirma as afirmações de Jean Duvignaud, acima citadas, acerca da memória histórica: uma reinvenção do passado a partir da reconstrução do presente estimulada pela vivência da pessoa que relembra:

"Tomamos do passado aquilo que nos parece útil às lutas em que estamos engajados no mundo onde vivemos. Lembro-me muito bem de ter-me interessado pela história do socialismo francês do fim do século XIX e começo do XX unicamente para compreender como um presidente do 
Conselho Socialista chamado Guy Mollet podia ocultar a tortura na Argélia e levar os exércitos franceses a combater para que a Argélia permanecesse sob o domínio da França.”

Os resultados de um trabalho de entrevistas com historiadores, sobre questões históricas ou teórico-metodológicas, é ambíguo por natureza. Trata-se de memória ou de história-conhecimento? É a dúvida, como vimos, mais recorrente. Ao mesmo tempo, é uma boa oportunidade de se fazer um exercício de reflexão em torno dessas noções a partir de práticas concretas.

Esta experiência mostrou algumas características possíveis desse tipo de trabalho. Em primeiro lugar, é preciso destacar o fator geracional. P. Vilar, de uma geração anterior a dos colegas entrevistados, recorreu mais às suas lembranças. Outro aspecto a ser assinalado são as modificações introduzidas pela oralidade no discurso do conhecimento. A exposição oral de um tema retira o autor do isolamento da escrita. A presença do interlocutor passa a fazer parte da composição do texto. Ainda que em silêncio, o outro é uma escuta. Finalmente, é importante perceber o papel do entrevistador; este coadjuvante do processo de produção do saber durante uma entrevista não quer ler um texto, quer ouvir, não quer a letra, quer a fala. Pesquisador "voyeur", pretende conhecer verdades, mas também sondar emoções. P. Vilar captou a expectativa oculta da entrevistadora e generosamente revelou suas sensibilidades ao responder a última questão colocada, cujo tema, Formas do conbecer histórico, foi assim apresentado:

'Entre a história 'positivista' do fim do século XIX e a história que é feita hoje há, como sabemos, uma grande distância. Dentre as transformações passadas pelas metodologias históricas, uma parece ser muito importante, qual seja, a construção de um novo conceito de tempo, atribuído à história-objeto e utilizado pela história-conhecimento. Podem ser citados como exemplos dessa construção a noção marxiana de estrutura e a 'dialética da duração' braudeliana.

Como pode ser vista esta transformação? Que fatores históricos a teriam provocado? Quais seriam - em nosso 
século - as principais referências teórico-metodológicas que informam os estudos históricos?

Após todos os acontecimentos que transformaram a História na última década, qual é hoje o papel do marxismo no conhecimento histórico?"

Disse Vilar:

"A última parte de sua última questão, no seu espírito, era certamente a mais importante. Mas, por discrição, por delicadeza, você deixou-a para o fim e a última palavra que pronunciou foi marxismo.

Eu compreendo muito bem que todos aqueles que me conheceram, que me apreciaram e compartilharam a convicção com a qual eu dava minhas aulas, perguntam-se hoje, provavelmente com alguma inquietude: 'Pierre Vilar, que sempre se declarou um historiador marxista, como está vendo, como está sentindo este fim de marxismo que é proclamado hoje insistentemente?' (...). Vamos, então, tentar ver o que pode ter de pessoal e, digamos, de sentimental naquilo que me inspiraram os eventos recentes. Mas vejamos, sobretudo, o que um historiador pode tirar das lições do presente.

Não tenho que esconder a melancolia que me invadiu o dia em que, no alto das torres do Kremlin, a bandeira vermelha cedeu lugar à bandeira da Rússia czarista e confesso, também, ter ficado muito chocado quando a capital do norte russo voltou a se chamar São Petesburgo e não mais Leningrado. Ainda que se pretendesse, eliminando Lenine, eliminar a idéia das violências do poder, não acho que o nome de Pedro, o Grande, tenha sido particularmente bem escolhido. E, tendo conversado com pessoas que viveram sua infância na atmosfera do cerco de Leningrado, creio que há qualquer coisa de vergonhoso em apagar esta lembrança. Pode-se dizer que estou no terreno do sentimento e não do intelecto, mas num tempo em que se fala sem cessar do simbólico, do imaginário, seria estranho não se levar em conta o que não é intelectual, o que é, em cada ser, existencial." 
E, finalizando seu depoimento:

"Estrutura, conjuntura, Marx, Simiand. Você reconhece aí, certamente, porque me conhece muito bem, minhas velhas preocupações. Eu ia dizer minhas manias! Como você me pediu uma visão pessoal da história, ou melhor, do método histórico, eu fui obrigado a colocar-me ou recolocarme em questão."

\section{Referências bibliográficas}

DUVIGNAUD, Jean. "Prefácio". In: HALBWACHS, M. A Memória Coletiva. São Paulo, Ed. Vértice / Ed. Revista dos Tribunais, 1990.

HALBWACHS, Maurice. A Memória Coletiva. São Paulo, Ed. Vértice / Ed. Revista dos Tribunais, 1990.

LE GOFF, Jaques. "Memória". In: Enciclopédia Einaudi. Imprensa Nacional/ Casa da Moeda, 1984.

NORA, Pierre. "Entre Mémoire et Histoire. La problématique des lieux". In: NORA, P. Les Lieux de Mémoire. Paris, Gallimard, 1984.

REBÉRIOUX, M. "Le Mur des Fédérés". In: NORA, P. Les Lieux de mémoire. V. 1 La République. Paris, Gallimard, 1984.

Resumo: A partir de um trabalho de entrevistas com historiadores franceses, no qual saberes históricos são produzidos na oralidade dos depoimentos, o artigo pretende examinar as noções de história, memória e historiografia e observar as interferências da memória na produção do discurso historiográfico.

Palavras-chave: Memória; História; Historiografia; Temporalidade.

Memory and Historiography. Limits and Possiblities of Approximation.

AвSTRACT: Based on interviews with French historians, in which historical knowledge is produced, this paper aims to discuss the concept of memory, history, historiography and to examine the interference of the memory on the history writing.

KEYWORDS: Memory; History; Historiography; Temporality. 